\title{
Lignin Removal From Aqueous Solution Using Calcium Lactate: The Effect of Polymers And Magnesium Hydroxide As A Flocculant Aids
}

A. Y. Zahrim *,1,2

A. Nasimah ${ }^{1,2}$

S. Rosalam ${ }^{1}$

1 Chemical Engineering Programme, Faculty of Engineering, Universiti Malaysia Sabah, Jalan UMS, 88400 Kota Kinabalu, Sabah, Malaysia.

2 Sustainable Palm Oil Research Unit, Universiti Malaysia Sabah, Jalan UMS, 88400 Kota Kinabalu, Sabah, Malaysia

*e-mail : zahrim@ums.edu.my

Palm oil mill effluent (POME) which is mainly associated with lignin has becoming a major concern due to its highly coloured appearance. The main colourant, i.e. lignin particles are difficult to be degraded in oil palm conventional biological ponding system. Coagulation/flocculation could remove the lignin prior to biological treatment and is considered vital to minimize the recalcitrance nature of palm oil mill effluent particles. In this study, the coagulation/flocculation process was investigated to remove lignin particles from aqueous solution. A non-toxic and biodegradable chemical i.e. calcium lactate was utilized as a destabilizer for the removal of lignin with an addition of several flocculants aid i.e. anionic polyacrylamide (APAM), polydimethyldiallylammonium chloride (polyDADMAC) and magnesium hydroxide. The effect of coagulant and flocculant aids dosage was investigated. From this study, it was found that the optimum condition was at $0.7 \mathrm{~g} / \mathrm{L}$ of calcium lactate and $0.5-1.0 \mathrm{mg} / \mathrm{L}$ of APAM with $\sim 64 \%$ of lignin removal. At concentration of $4 \mathrm{mg} / \mathrm{L}$, the removal of lignin for APAM and polyDADMAC is similar. This result shows that the calcium lactate has potential as a coagulant and the efficiency can be enhanced with an addition of polymeric flocculant aids.

Keywords: Calcium lactate, coagulation/flocculation, lignin, zeta potential, polymer, magnesium hydroxide.

\section{INTRODUCTION}

Lignin is an important particles that need to be considered for effective treatment of palm oil mill effluent (POME)
(Table 1) since it is resistant to biodegradation at high concentration (Ho et al., 1984).

Lignin is a complex aromatic polymer that exist in plant species within ranges 
20 Lignin Removal From Aqueous Solution Using Calcium Lactate: The Effect Of Polymers And Magnesium Hydroxide As A Flocculant Aids

Table 1. The distribution of chemical constituents between the soluble and the particulate fractions of POME (Ho et al., 1984)

\begin{tabular}{|c|c|c|c|}
\hline & $\mathrm{POME}^{\mathrm{a}}$ & $\begin{array}{l}\text { Particulate } \\
\text { fraction }^{a}\end{array}$ & $\begin{array}{c}\text { Soluble } \\
\text { fraction }^{\text {a }}\end{array}$ \\
\hline Total solids & 4.24 & & \\
\hline Dissolved solids & & & 2.012 \\
\hline Suspended solids & & 1.942 & \\
\hline 'Free' oil drops & 0.303 & & \\
\hline $\begin{array}{l}\text { Extractable oil } \\
\text { Ash }\end{array}$ & 1.024 & 0.673 & 0.021 \\
\hline total & 0.602 & 0.18 & 0.421 \\
\hline water-insoluble & 0.322 & 0.156 & 0.169 \\
\hline acid-insoluble & 0.110 & 0.108 & 0.018 \\
\hline $\begin{array}{l}\text { Ethanol/benzene } \\
\text { extract }\end{array}$ & 0.376 & 0.102 & 0.283 \\
\hline $\begin{array}{l}\text { Nitrogen content } \\
\text { total } \\
\text { extractive-free }\end{array}$ & $\begin{array}{l}0.071 \\
0.061\end{array}$ & $\begin{array}{l}0.045 \\
0.038\end{array}$ & 0.022 \\
\hline $\begin{array}{l}\text { Acid-insoluble } \\
\text { lignin }\end{array}$ & 0.470 & 0.412 & \\
\hline Phenolics & 0.584 & 0.246 & 0.335 \\
\hline Glucode (free) & 0.006 & & 0.014 \\
\hline Reducing sugars & 0.160 & & 0.145 \\
\hline Starch & 0.052 & 0.008 & 0.036 \\
\hline Pectin & 0.341 & 0.031 & 0.328 \\
\hline Total glucose ${ }^{c}$ & 0.200 & 0.200 & \\
\hline $\begin{array}{l}\text { Total reducing } \\
\text { sugars }^{c}\end{array}$ & 0.607 & 0.373 & \\
\hline $\begin{array}{l}\text { Total } \\
\text { carbohydrates }^{c}\end{array}$ & 0.767 & 0.416 & $0.390^{d}$ \\
\hline Pentosans & 0.170 & 0.165 & \\
\hline Holocellulose & 0.731 & 0.574 & \\
\hline$\alpha-$ cellulose & 0.591 & 0.434 & \\
\hline$\beta$-cellulose & 0.027 & 0.024 & \\
\hline$\gamma$-cellulose & 0.113 & 0.116 & \\
\hline
\end{tabular}

${ }^{a}$ In g/100 ml POME.

${ }^{\mathrm{b}}$ Values obtained from extractive-free samples.

'Values obtained after acid hydrolysis.

${ }^{\mathrm{d}}$ Only the total soluble-carbohydrate concentration, hydrolysis was not necessary.

from (20-40)\% of the dry mass of wood (Maximova et al., 2001). Lignin containing wastewater is commonly found in the agricultural industries such as from pulp and paper process (Chang et al., 2004), olive oil processing (Haddadin et al., 2002) and palm oil mill process (Neoh et al.,
2014). The presence of lignin in wastewater contribute to the dark brown colour of wastewater and could increase organic pollution load (Betancur et al., 2009). The lignin containing wastewater are of environmental and health concern due to its toxicity and carcinogenic by- 
product(Neoh et al., 2014).

Since lignin is difficult to be degraded chemically and biologically ( $\mathrm{Wu}$ et al., 2005), a number of treatment methods were investigated in order to remove lignin from wastewater. Methods such as photochemical UV/TiO 2 oxidizing process (Chang et al., 2004), adsorption (Maximova et al., 2001), electrocoagulation process (Ugurlu et al., 2008), filtration/flocculation (Wang et al., 2014) and flocculation (Piazza et al., 2014). In this study, the physico-chemical method (coagulation/flocculation) was proposed to be employed due to its simplicity, low cost, good removal efficiency and easy onsite implementation (Karthik et al., 2008). The addition of suitable polymeric flocculants could enhance the performance of the coagulation/flocculation by producing large flocs and less resistant to shear stress (Zahrim and Hilal, 2011). In recent years, several authors have investigated the roles of calcium lactate and magnesium hydroxide as a coagulant and coagulant aids in a coagulation/flocculation process (Zhao et al., 2014, Vandamme et al., 2012, Devesa-Rey et al., 2011, Devesa-Rey et al., 2012). To date, there is no published study that has been carried out for the removal of lignin from wastewater by using calcium lactate-polymer and calcium lactatemagnesium hydroxide.

The aim of this work is to identify the optimum conditions for lignin removal by coagulation/flocculation with the addition of calcium lactate as a coagulant and different types of flocculants aids i.e.APAM, polyDADMAC and magnesium hydroxide as flocculants aid.These flocculants aids have been chosen in this study since it is effective based on previous studies (Zahrim et al., 2010, Zahrim et al., 2011, Schlesinger et al., 2012, Zahrim et al., 2014).

\section{METHODOLOGY}

\section{Materials}

The $2000 \mathrm{mg} / \mathrm{L}$ lignin solution was prepared by dissolving appropriate amount of lignin (alkali) powder (SigmaAldrich, USA) in distilled water. Similarly, the stock solutions of $50 \mathrm{~g} / \mathrm{L}$ calcium lactate (Molecular mass $308.32 \mathrm{~g} / \mathrm{mol}$ ) (Merck, Germany) and 1000mg/L magnesium hydroxide (Molecular mass $58.32 \mathrm{~g} / \mathrm{mol}$ ) (Sigma-Aldrich, USA) also were prepared by dissolving their powder form in distilled water. In addition, the $0.2 \%$ polymers solution i.e. polyDADMAC (Tramfloc ${ }^{\circledR} 724,40 w t \%$ ) and APAM (Tramfloc ${ }^{\circledR} 141$, 39wt\%) were also prepared by dissolving in distilled water and were used within 24 hours.

\section{Jar Test Methods}

A standard flocculator apparatus (Phipps \& Birds) equipped with stainless steel paddles and stirrer was used for the coagulation/flocculation tests. During the jar tests, the appropriate volume of lignin stock solution was transferred into the round jar. An appropriate dosage of calcium lactate was added to the solution in the jar. The aqueous solution was then rapidly mixed at a paddle speed of 258 rpm for $3 \mathrm{~min}$. Predetermined dosage of APAM, polyDADMAC and magnesium hydroxide were added to the solution in the jar, making the total volume of $500 \mathrm{~mL}$, followed by slow mixing for $10 \mathrm{~min}$ at 39 
22 Lignin Removal From Aqueous Solution Using Calcium Lactate: The Effect Of Polymers And Magnesium Hydroxide As A Flocculant Aids

rpm. After allowing settling to occur for 20 min, about $25 \mathrm{~mL}$ of the liquid was withdrawn using a pipette from a height of about $3 \mathrm{~cm}$ below the liquid surface in each jar(Zahrim et al., 2010).

\section{Analytical Methods}

The lignin content was tested by using Biospectrometer (Eppendorf), absorbance at $\lambda_{\max }=286 \mathrm{~nm}$. The $\mathrm{pH}$ and conductivity was measured by using meter $\mathrm{HI}$ 9611-5, Hanna Instrument. The zeta potential was obtained by using Malvern-Zetasizer Nano Series model ZS machine.

\section{Statistical Analysis}

Each data point was taken as the average of three measurements with standard deviation (STDEV).

\section{RESULT AND DISCUSSIONS}

\section{Effect of Calcium Lactate Dosage}

Figure 1,2, and 3 shows the effect of calcium lactate dosage during coagulation/flocculation of lignin. Various dosages of calcium lactate $(0.1 \mathrm{~g} / \mathrm{L}, 0.3 \mathrm{~g} / \mathrm{L}$, $0.5 \mathrm{~g} / \mathrm{L}, \quad 0.7 \mathrm{~g} / \mathrm{L}, \quad 0.9 \mathrm{~g} / \mathrm{L}$ and $1.2 \mathrm{~g} / \mathrm{L}$ ) were used and several parameters including (\% lignin removal, zeta potential, $\mathrm{pH}$ and conductivity) were tested.

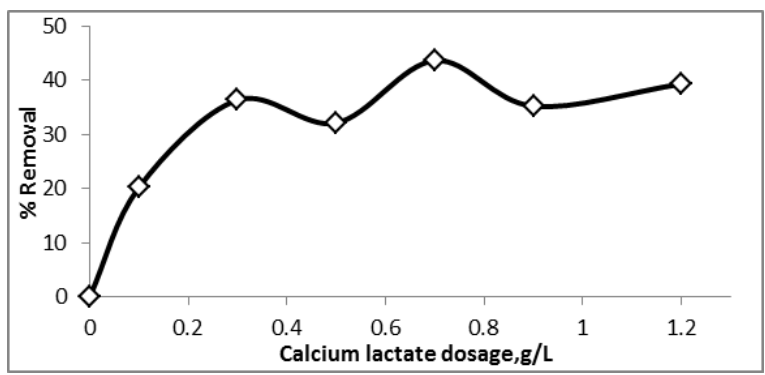

Fig. 1: Effect of calcium lactate dosage on the $\%$ removal during coagulation/flocculation of lignin.

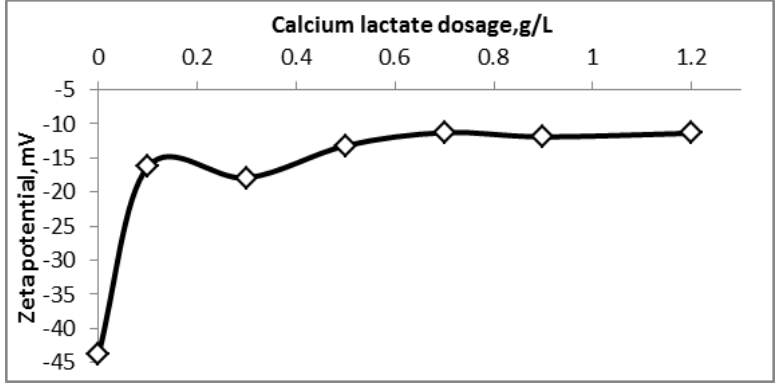

Fig. 2: Effect of calcium lactate dosage on zeta potential during coagulation/flocculation of lignin.

The untreated lignin shows that the lignin particle has negative surface charge i.e. $-44 \mathrm{mV}$ (Figure 2). The particles with high negative zeta potential value indicates its superior metal-binding capability, where it has a potential to bind with a positively charged solutes (Betancur et al., 2009). The addition of calcium lactate increase lignin removal and tend to move zeta potential near zero. At near zero zeta potential, the particles tend to agglomerate might be due to the reduction the electrical double layer ( $\mathrm{Ma}$ et al., 2003).The maximum removal i.e. $44 \%$ achieved at $0.7 \mathrm{~g} / \mathrm{L}$ dosage. Generally, at low pHs, metal salts apply a charge neutralization mechanism, while, at higher dosages and $\mathrm{pH}$, precipitation might occur.(Devesa-Rey et al., 2011) had studied on the use of calcium lactate as a coagulant-flocculant at dosage $2-10 \mathrm{~g} / \mathrm{L}$ and $\mathrm{pH}$ 5-7 for the reducing of water turbidity. It was reported, the greatest reductions of turbidity were achieved with a moderate concentration of calcium lactate at $\mathrm{pH}$ 5. While, (Leentvaar and Rebhun, 1982)had reported the removal of suspended solids from sewage wastewater 


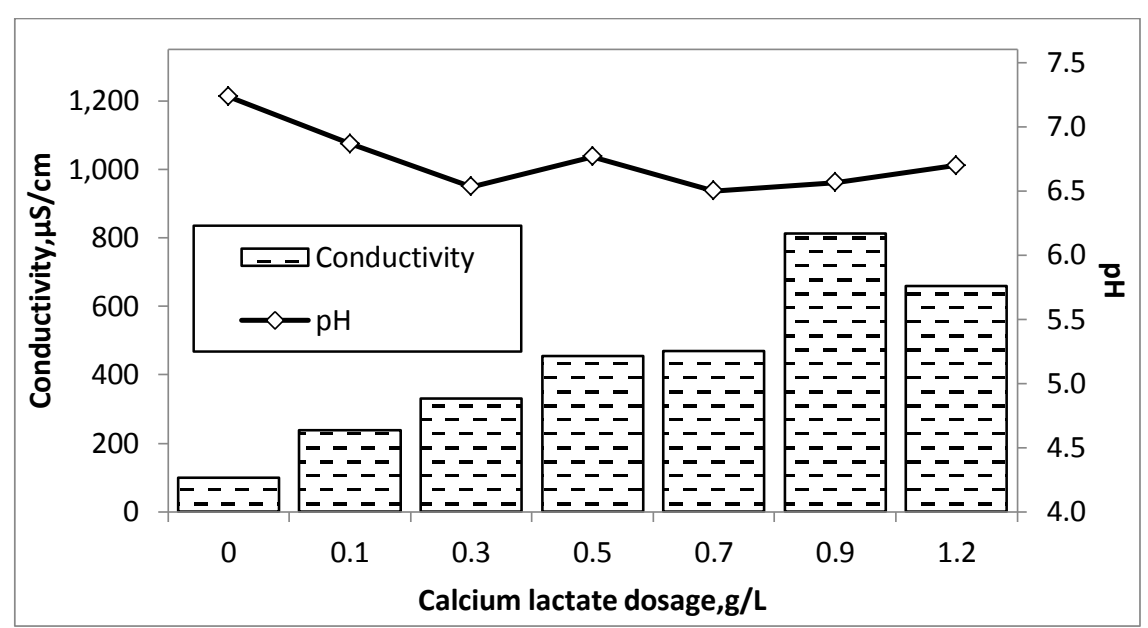

Fig. 3: Effect of calcium lactate dosage on the $\mathrm{pH}$ and conductivity during coagulation/flocculation of lignin.

by using precipitated calcium carbonate as coagulant aids at $\mathrm{pH} 10$ and higher was due to the sweep coagulation mechanism. In this study, at final $\mathrm{pH}$ range between 6.4-7.0 (Figure 3), the removal of lignin particles using calcium lactate might indicates the combination of charge neutralization-sweep flocculation mechanism.

Figure 3 shows the $\mathrm{pH}$ decreased from 7.2 into $\mathrm{pH}(>6.4$ to $<7.0)$, while, the conductivity increased from $100 \mu \mathrm{S} / \mathrm{cm}$ to $813 \mu \mathrm{S} / \mathrm{cm}$, at various dosage of calcium lactate. The presence of calcium lactate increased the conductivity due to the presence of salt (Levlin, 2008).

\section{Effect of APAM, polyDADMAC and Magnesium Hydroxide as Flocculants Aid}

Figure 4, 5, and 6 shows the effect of flocculants aid dosage during coagulation/flocculation of lignin. Based on the previous finding, the dosage of calcium lactate was fixed at $0.7 \mathrm{~g} / \mathrm{L}$. Then, different types of flocculants aid (APAM, polyDADMAC and magnesium hydroxide) were applied. For each flocculant aids, various dosages $(0.5 \mathrm{mg} / \mathrm{L}, 1 \mathrm{mg} / \mathrm{L}, 2 \mathrm{mg} / \mathrm{L}$, $4 \mathrm{mg} / \mathrm{L}$ and $6 \mathrm{mg} / \mathrm{L}$ ) were used and several parameters (\% removal, zeta potential, $\mathrm{pH}$ and conductivity) were investigated.

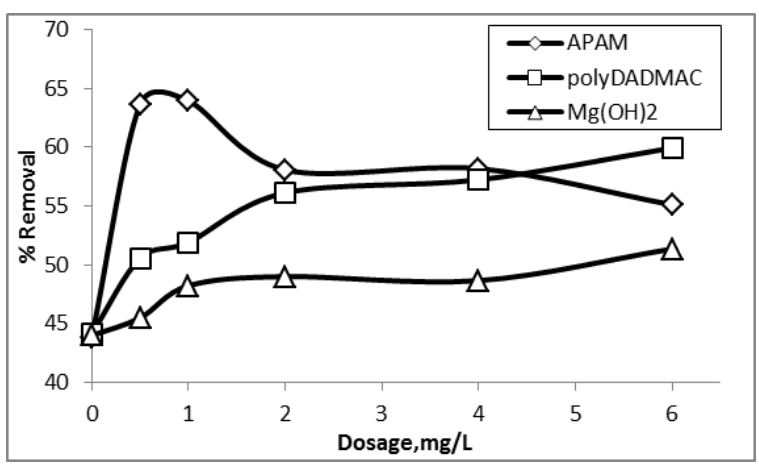

Fig. 4: Effect of flocculants aid dosage on the removal during coagulation/flocculation of lignin with $0.7 \mathrm{~g} / \mathrm{L}$ calcium lactate.

The graph shows that the addition of polymer as flocculants aid enhanced the removal of lignin compared with the magnesium hydroxide. The application of APAM at as flocculant aids shows highest removal of $64 \%$ due to its bridging effect (Peng and Di, 1994) and then causing faster settling rate (Nasser and James, 2007).(Peng and Di, 1994) suggested that 
24 Lignin Removal From Aqueous Solution Using Calcium Lactate: The Effect Of Polymers And Magnesium Hydroxide As A Flocculant Aids

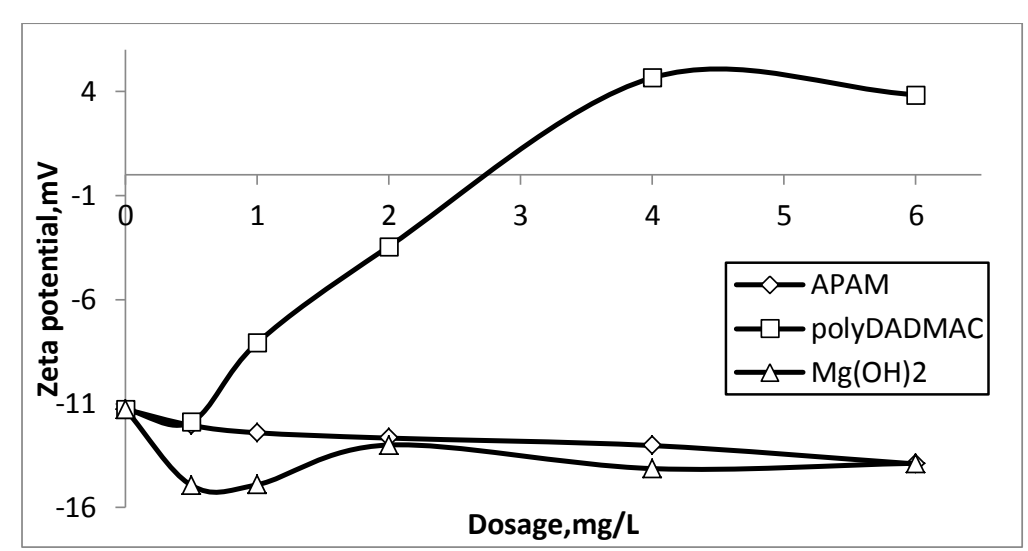

Fig. 5: Effect of flocculants aid dosage on zeta potential during coagulation/flocculation of lignin with $0.7 \mathrm{~g} / \mathrm{L}$ calcium lactate.

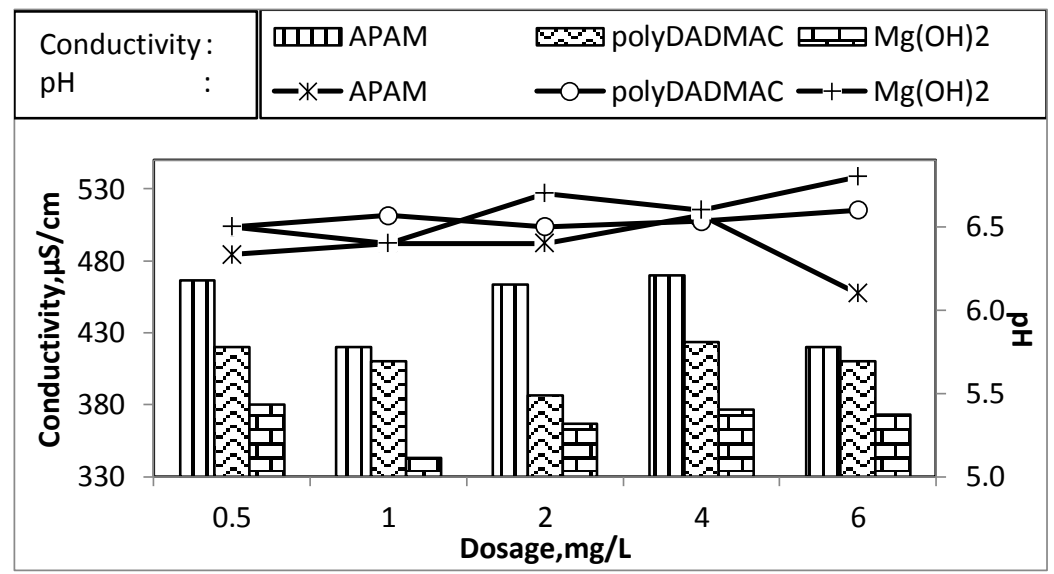

Fig. 6: Effect of flocculants aid dosage on the $\mathrm{pH}$ and conductivity during coagulation/flocculation of lignin with $0.7 \mathrm{~g} / \mathrm{L}$ calcium lactate $(\mathrm{pH}$ and conductivity without coagulant aids, 6.5 and $470 \mu \mathrm{S} / \mathrm{cm}$ ).

the APAM able to form larger flocs through a hydrogen bonding with the water surfaces and calcium ions through its amide groups $\left(-\mathrm{CONH}_{2}\right)$ and carboxylic groups (-COO).After $1 \mathrm{mg} / \mathrm{L}$ of APAM, the percentage removal decreased due to the increases in electrostatic repulsion and consequently restabilisation occurs (Nasser and James, 2007). (Razali et al., 2012) had reported that the flocculation of lignin using polyDADMACis dominated by charge neutralization mechanism. The addition of magnesium hydroxide shows less removal efficiency of lignin since it apply a charge neutralization and adsorptive coagulation mechanism (Gao et al., 2007). At the dosage of $4 \mathrm{mg} / \mathrm{L}$, the removal of lignin particles is similar between APAM and polyDADMAC might be due to the fact that polyDADMAC could act as a bridge to connect the destabilized lignin particles. It can be seen also that the addition of magnesium hydroxide has lower lignin removal than both polymers due to the absence of bridging property.

From Figure 5, the zeta potential value shows greater than zero value at concentration $>2.8 \mathrm{mg} / \mathrm{L}$ of polyDADMAC dosage and keep increasing as the amount 
of polyDADMAC increased. This trend might be explained by the presence of unreacted polyDADMAC (cationic polymer) during coagulation/flocculation process. There is a small change towards more negatively charged of particle after an addition of APAM might be caused by the free negatively polymer chain molecules (Nasser and James, 2006).

Figure 6 shows the $\mathrm{pH}$ and conductivity that was maintainn within the range of 6.3 to 6.8 and $343 \mu \mathrm{S} / \mathrm{cm}$ to $470 \mu \mathrm{S} / \mathrm{cm}$ after the addition of various flocculants aid dosage. The stable $\mathrm{pH}$ is important since several conventional coagulants such as iron and alum based coagulants tend to turn the treated wastewater into acidic conditions at high dosage application.

\section{CONCLUSSION}

From this study, it can be concluded that the suitable dosage of calcium lactate with an addition of flocculant aids has potential for the agglomeration of lignin. Maximum lignin removal was achieved at $0.7 \mathrm{~g} / \mathrm{L}$ of calcium lactate and $(0.5-1.0) \mathrm{g} / \mathrm{L}$ of APAM with $\sim 64 \%$ lignin removal. At this optimum condition, $\mathrm{pH}$ and conductivity are stable at 6.35 and $443 \mu \mathrm{S} / \mathrm{cm}$, respectively. Zeta potential shows a small change towards more negatively charged of particle after an addition of APAM caused by unreacted negatively molecules.

\section{ACKNOWLEDGEMENT}

The authors would like to thank Ministry of Education, Malaysia for awarding grant,
FRGS/2/2013/TK05/UMS/02/1 for this project.

\section{REFERENCES}

1. BETANCUR, M., BONELLI, P. R., VELAISQUEZ, J. A. \& CUKIERMAN, A. L. (2009) Potentiality of lignin from the Kraft pulping process for removal of trace nickel from wastewater: Effect of demineralisation. Bioresource Technology.

2. BETANCUR, M., BONELLI, P. R., VELAISQUEZ, J. A. \& CUKIERMAN, A. L. (2009) Potentiality of lignin from the Kraft pulping process for removal of trace nickel from wastewater: Effect of demineralisation. Bioresource Technology.

3. CHANG, C.-N., MA, Y.-S., FANG, G.-C., CHAO, A. C., TSAI, M.-C. \& SUNG, H.-F. (2004) Decolorizing of lignin wastewater using the photochemical UV/TiO2 process. Chemosphere, 56, 1011-1017.

4. DEVESA-REY, R., BUSTOS, G., CRUZ, J. M. \& MOLDES, A. B. (2012) Evaluation of Non-Conventional Coagulants to Remove Turbidity from Water. Water, Air, \& Soil Pollution, 223, 591-598.

5. DEVESA-REY, R., FERNANDEZ, N., CRUZ, J. M. \& MOLDES, A. B. (2011) Optimization of the dose of calcium lactate as a new coagulant for the coagulation-flocculation of suspended particles in water. Desalination, 280, 63-71.

6. GAO, B.-Y., YUE, Q.-Y., WANG, Y. \& ZHOU, W.-Z. (2007) Color removal from dye-containing wastewater by magnesium chloride. Journal of 
26 Lignin Removal From Aqueous Solution Using Calcium Lactate: The Effect Of Polymers And Magnesium Hydroxide As A Flocculant Aids

Environmental Management, 82, 167172.

7. HADDADIN, M. S., AL-NATOUR, R., ALQSOUS, S. \& ROBINSON, R. K. (2002) Bio-degradation of lignin in olive pomace by freshly-isolated species of Basidiomycete. Bioresource Technology, 82, 131-137.

8. HO, C. C., TAN, Y. K. \& WANG, C. W. (1984) The distribution of chemical constituents between the soluble and the particulate fractions of palm oil mill effluent and its significance on its utilisation/treatment. Agricultural Wastes, 11, 61-71.

9. KARTHIK, M., DAFALE, N., PATHE, P. \& NANDY, T. (2008) Biodegradability enhancement of purified terephthalic acid wastewater by coagulationflocculation process as pretreatment. Journal of Hazardous Materials, 154, 721-730.

10. LEENTVAAR，J. \& REBHUN， M. (1982) Effect of magnesium and calcium precipitation on coagulationflocculation with lime. Water Research, $16,655-662$.

11. LEVLIN, E. (2008) Conductivity measurements for controlling municipal wastewater. Dep. of Land and Water Resources Engineering, KTH, S10044 Stockholm, Sweden.

12. MA, J., WANG, C. \& PENG, K. W. (2003) Electrophoretic deposition of porous hydroxyapatite scaffold. Biomaterials, 24, 3505-3510.

13. MAXIMOVA， N., A-STERBERG, M., KOLJONEN, K. \& STENIUS, P. (2001) Lignin adsorption on cellulose fibre surfaces: Effect on surface chemistry, surface morphology and paper strength. Cellulose, 8, 113-125.

14. NASSER, M. S. \& JAMES, A. E. (2006) The effect of polyacrylamide charge density and molecular weight on the flocculation and sedimentation behaviour of kaolinite suspensions. Separation and Purification Technology, 52, 241-252.

15. NASSER, M. S. \& JAMES, A. E. (2007) Effect of polyacrylamide polymers on floc size and rheological behaviour of kaolinite suspensions. Colloids and Surfaces A: Physicochemical and Engineering Aspects, 301, 311-322.

16. NEOH, C., LAM, C., LIM, C., YAHYA, A. \& IBRAHIM, Z. (2014) Decolorization of palm oil mill effluent using growing cultures of Curvularia clavata. Environmental Science and Pollution Research, 21, 4397-4408.

17. PENG, F. F. \& DI, P. (1994) Effect of Multivalent Saltsâ€"Calcium and Aluminum on the Flocculation of Kaolin Suspension with Anionic Polyacrylamide. Journal of Colloid and Interface Science, 164, 229-237.

18. PIAZZA, G. J., LORA, J. H. \& GARCIA, R. A. (2014) Flocculation of high purity wheat straw soda lignin. Bioresource Technology, 152, 548-551.

19. RAZALI, M. A. A., AHMAD, Z.\&ARIFFIN, A. (2012) Treatment of Pulp and Paper Mill Wastewater with Various Molecular Weight of PolyDADMAC Induced Flocculation with Polyacrylamide in the Hybrid SystemAdvances in Chemical Engineering and Science, 2.

20. SCHLESINGER， A., EISENSTADT, D., BAR-GIL, A., CARMELY, H., EINBINDER, S. \& GRESSEL, J. (2012) Inexpensive non-toxic flocculation of microalgae 
contradicts theories; overcoming a major hurdle to bulk algal production. Biotechnology Advances, 30, 10231030.

21. UGURLU, M., GURSES, A., DOGAR, A. \& YALCIN, M. (2008) The removal of lignin and phenol from paper mill effluents by electrocoagulation. Journal of Environmental Management, 87, 420-428.

22. VANDAMME, D., FOUBERT, I., FRAEYE, I., MEESSCHAERT, B. \& MUYLAERT, K. (2012) Flocculation of Chlorella vulgaris induced by high $\mathrm{pH}$ : Role of magnesium and calcium and practical implications. Bioresource Technology, 105, 114-119.

23. WANG, Q., SARWAR JAHAN, M., LIU, S., MIAO, Q. \& NI, Y. (2014) Lignin removal enhancement from prehydrolysis liquor of kraft-based dissolving pulp production by laccase- induced polymerization. Bioresource Technology. 24. WU, J., XIAO, Y.-Z. \& YU, H.-Q. (2005) Degradation of lignin in pulp mill wastewaters by white-rot fungi on biofilm. Bioresource Technology, 96, 1357-1363.

25. ZAHRIM， A. Y. \& HILAL, N. (2011) Treatment of highly concentrated dye solution by coagulation/flocculation, sand filtration and nanofiltration. Water Resources and Industry, 3, 23-34.
26. ZAHRIM, A. Y., NASIMAH, A. \& HILAL, N. (2014) Pollutants analysis during conventional palm oil mill effluent (POME) ponding system and decolourisation of anaerobically treated POME via calcium lactatepolyacrylamide. Journal of Water Process Engineering, 4, 159-165.

27. ZAHRIM, A. Y., TIZAOUI, C. \& HILAL, N. (2010) Evaluation of several commercial synthetic polymers as flocculant aids for removal of highly concentrated C.I. Acid Black 210 dye. Journal of Hazardous Materials, 182, 624-630.

28. ZAHRIM, A. Y., TIZAOUI, C. \& HILAL, N. (2011) Removal of highly concentrated industrial grade leather dye: Study on several flocculation and sand filtration parameters. Separation Science and Technology, 46, 883-892.

29. ZHAO, J., SU, R., GUO, X., LI, W. \& FENG, N. (2014) Role of mixing conditions on coagulation performance and flocs breakage formed by magnesium hydroxide. Journal of the Taiwan Institute of Chemical Engineers. 